\title{
Cell Propagation of Cholera Toxin CTA ADP-Ribosylating Factor by Exosome Mediated Transfer
}

\author{
Cristiana Zanetti ${ }^{1}$, Angelo Gallina ${ }^{2}$, Alessia Fabbri ${ }^{3}$, Sofia Parisi ${ }^{3}$, Angela Palermo ${ }^{3}$ (D), \\ Katia Fecchi ${ }^{3}$, Zaira Boussadia ${ }^{3}$ (D), Maria Carollo 4 (i), Mario Falchi ${ }^{5}$, Luca Pasquini ${ }^{4}$, \\ Maria Luisa Fiani ${ }^{3, *}$ and Massimo Sargiacomo ${ }^{3, *}$ \\ 1 Department of Oncology and Molecular Medicine, Istituto Superiore di Sanità, Viale Regina Elena 299, \\ 00161 Rome, Italy; cristiana.zanetti@iss.it \\ 2 Department of Neurosciences, Istituto Superiore di Sanità, Viale Regina Elena 299, 00161 Rome, Italy; \\ gallinaangelo@yahoo.com \\ 3 National Center for Global Health, Istituto Superiore di Sanità, Viale Regina Elena 299, 00161 Rome, Italy; \\ alessia.fabbri@iss.it (A.F.); sofia.parisi91@gmail.com (S.P.); annica86@hotmail.it (A.P.); \\ katia.fecchi@iss.it (K.F.); zaira.boussadia@iss.it (Z.B.) \\ 4 Core Facilities-Cytometry Unit, Istituto Superiore di Sanità, Viale Regina Elena 299, 00161 Rome, Italy; \\ maria.carollo@iss.it (M.C.); luca.pasquini@iss.it (L.P.) \\ 5 National AIDS Center, Istituto Superiore di Sanità, Viale Regina Elena 299, 00161 Rome, Italy; \\ mario.falchi@iss.it \\ * $\quad$ Correspondence: maria.fiani@iss.it (M.L.F.); massimo.sargiacomo@iss.it (M.S.); Tel.: +39-06-4990-2518 (M.S.)
}

Received: 22 April 2018; Accepted: 16 May 2018; Published: 19 May 2018

Abstract: In this study, we report how the cholera toxin (CT) A subunit (CTA), the enzyme moiety responsible for signaling alteration in host cells, enters the exosomal pathway, secretes extracellularly, transmits itself to a cell population. The first evidence for long-term transmission of $\mathrm{CT}^{\prime}$ s toxic effect via extracellular vesicles was obtained in Chinese hamster ovary $(\mathrm{CHO})$ cells. To follow the $\mathrm{CT}$ intracellular route towards exosome secretion, we used a novel strategy for generating metabolically-labeled fluorescent exosomes that can be counted by flow cytometry assay (FACS) and characterized. Our results clearly show the association of CT with exosomes, together with the heat shock protein 90 (HSP90) and Protein Disulfide Isomerase (PDI) molecules, proteins required for translocation of CTA across the ER membrane into the cytoplasm. Confocal microscopy showed direct internalization of $\mathrm{CT}$ containing fluorescent exo into $\mathrm{CHO}$ cells coupled with morphological changes in the recipient cells that are characteristic of CT action. Moreover, Me665 cells treated with CT-containing exosomes showed an increase in Adenosine 3', 5'-Cyclic Monophosphate (cAMP) level, reaching levels comparable to those seen in cells exposed directly to CT. Our results prompt the idea that $\mathrm{CT}$ can exploit an exosome-mediated cell communication pathway to extend its pathophysiological action beyond an initial host cell, into a multitude of cells. This finding could have implications for cholera disease pathogenesis and epidemiology.

Keywords: cholera toxin; exosomes; endocytic pathway; Caveolin-1; monosialganglioside GM1

\section{Introduction}

In the 21st century, cholera remains an epidemic or endemic disease in many parts of the world. It is caused by some serogroups of the bacterium Vibrio cholerae which colonize the small intestine and secrete the Cholera Toxin (CT) protein [1]. CT is made up of two major subunits, A and B [2], similar to other members of the AB5 family of toxins, and, once secreted by bacteria as a holotoxin, enters host 
cells by hijacking endogenous internalization and intracellular trafficking pathways, culminating in the induction of toxicity [3]. The A subunit (CTA) represents the enzymatic portion of the enterotoxin, and is composed of a globular A1 domain (CTA1), which possesses Adenosine 5'-diphosphate (ADP)-ribosylating activity, and the A2 domain (CTA2), that stabilizes the homo-pentameric $B$ subunits (CTB) by noncovalent binding.

Internalization of CT depends on interaction of the CTB subunits of the toxin with GM1 gangliosides. GM1 gangliosides are typically concentrated in organized signaling centers such as lipid rafts and caveolae [4-6]. Localization of the cholera toxin within caveolae has triggered the idea that these sites may constitute clathrin independent carriers of the toxin. Although there is no evidence that CT enters cells specifically through the caveolae pathway, experiments have shown that GM1 and Caveolin-1 (Cav-1) expression levels are selective factors for the caveolae/raft-dependent endocytosis of cholera toxin [7].

Extracellular secretion gives rise to a variety of vesicles (EV), including those strictly derived from MVBs and properly defined as exosomes. Exosomes (exo) are vesicles of 30-150 nm diameter that are secreted by cells into their environment. They are generated by inward budding of endosomal membranes to form multivesicular bodies (MVBs). Fusion of MVBs with the plasma membrane typically releases multiple exosomes [8,9]. An increasing number of intracellular molecules has been reported to enter into exosomes and to be secreted in the extracellular space, suggesting a role for these vesicles as shuttles that deliver cargo molecules from one cell to another, and whose contents may be used for monitoring the metabolic state of the cell [10-12].

A few studies have examined the involvement of exo in toxin trafficking. The lethal factor (LF) of Anthrax toxin, a major Bacillus anthracis virulence factor, is translocated into the lumen of endosomal intraluminal vesicles (ILVs). It persists in them for days, and can be transmitted to neighboring cells via exosomes [13]. Trichosanthin (TCS), a plant toxin, is incorporated into intraluminal vesicles of the MVB, and is then secreted in association with exosomes upon fusion of the MVB with the plasma membrane [14]. In this paper, we show that that internalized CT molecules are sorted into MVBs, and are secreted as exosomes by Me665 and CHO cells. Furthermore, we show that CT contained in exosomes may be transferred to naïve recipient cells, and is able to induce morphological and functional changes typical of CT intoxication. To follow the transport of $\mathrm{CT}$ along the MVB/exosome route, we take advantage of a new methodology based on the fluorescent labeling of the phospholipid bilayer of exosomes that enabled us to trace and quantify exosome secretion [15].

\section{Results}

\subsection{Extracellular Vesicles Isolated from $\mathrm{CHO}$ and Me665 Cells Upon CT Incubation Contain Cholera Toxin}

We previously reported that Cav-1, a structural component of caveolae formation, is highly expressed in human metastatic melanoma cell lines, and is retrieved in isolated fractions of extracellular vesicles (EV) [16]. Since caveolae are known locations for CTB binding to GM1 gangliosides, we hypothesized that Cav-1 and CT might share the endocytic pathway that leads to EV secretion. We first evaluated the relative levels of GM1 and Cav-1 in Me665 melanoma cells and CHO cells. Figure 1A shows that both cell types expressed these molecules, with higher levels in Me665 cells.

To determine whether CT was secreted in EVs, culture supernatants from CT treated Me665 and $\mathrm{CHO}$ cells $\left(2 \times 10^{7}\right.$ cells for both cell lines) were subjected to differential centrifugation to isolate EVs, and vesicle pellets were analyzed by western blot for CT presence. Both CTA and CTB subunits were present in EV pellets from both cell types, and were slightly more abundant in Me665 cells (Figure 1B).

To determine if CT carried by EVs was capable of inducing morphological changes in cells that had not been directly exposed to CT, we used a well-established CHO cell morphological assay [17]. In this experiment, $\mathrm{CHO}$ cells were exposed to $12 \mathrm{nM} \mathrm{CT}$ for $2 \mathrm{~h}$, washed, and incubated with fresh medium (without CT) for $24 \mathrm{~h}$ at $37^{\circ} \mathrm{C}$. After removal of the conditioned medium, fresh medium was added (twice), each time for an additional $24 \mathrm{~h}$. EVs were purified from each of the conditioned 
media samples (EV-CT $24 \mathrm{~h}$, EV-CT $48 \mathrm{~h}$ and EV-CT $72 \mathrm{~h}$ ), and as a control, EVs were purified from replicate $\mathrm{CHO}$ cells treated in an identical manner, but without CT-exposure. To determine if the $\mathrm{CT}$ carried by EVs was capable of inducing biological effects in cells that had not been directly exposed to $\mathrm{CT}$, we used a well-established morphological assay based on $\mathrm{CHO}$ cell morphology [17]. Freshly trypsinized CHO cells were treated for $6 \mathrm{~h}$ with $5 \mu \mathrm{g}$ of EVs from the CT-exposed cells, or with $5 \mu \mathrm{g}$ of EVs from control cells. As a positive control, replicates cells were directly exposed to $12 \mathrm{nMCT}$. Under normal conditions, most untreated cells remain round (Figure 1C) (even after overnight culture, not shown). In contrast, when directly exposed to $12 \mathrm{nM} \mathrm{CT}$, the majority of cells became bipolar and elongated. In the case of cells exposed to EVs derived from CT treated cells, $60-80 \%$ became bipolar and elongated, comparable to cells exposed directly to $12 \mathrm{nM} \mathrm{CT} \mathrm{(Figure} \mathrm{1C).} \mathrm{Notably,} \mathrm{EVs}$ secreted after 48 or $72 \mathrm{~h}$ from cells challenged with CT were also able to induce a morphological change, indicating that functionally active $\mathrm{CT}$ is present in the EVs.
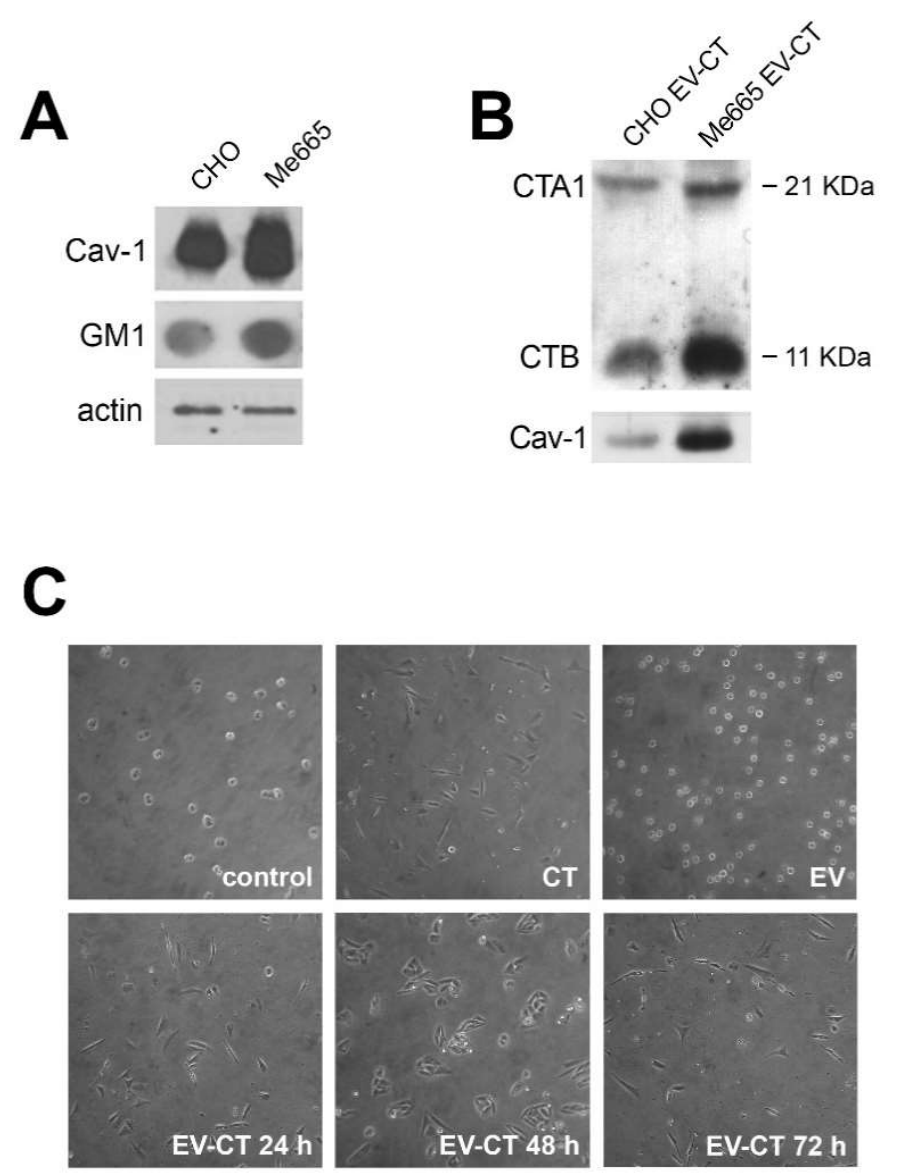

Figure 1. Expression of Cav-1 and GM1 in CHO and Me665 cells and morphological changes in $\mathrm{CHO}$ cells induced by CT-positive EVs (EV-CT) (A) Western blot analysis for Cav-1 and Dot blot analysis for GM1 of CHO and Me665 cell lines. For SDS-PAGE $30 \mu \mathrm{g}$ of cell lysates were used and for Dot Blot $40 \mu \mathrm{g} /$ dot. The presence of GM1 was assessed using horseradish peroxidase (HRP)-conjugated CTB. Actin is shown for normalization; (B) EVs collected from supernatants of CHO and Me665 cells treated with CT were run on a SDS-PAGE gel in reducing conditions Western blot analysis with a polyclonal antibody for Cav-1 and CT is shown; (C) Optical light microscope (Nikon, magnification $\times 10$ ) analysis of $\mathrm{CHO}$ cells upon addition of extracellular vesicles from control or CT treated $\mathrm{CHO}$ cells. EV were collected at different times from cell-conditioned medium, and isolated by differential ultracentrifugation. After isolation, $5 \mu \mathrm{g}$ of $\mathrm{EV}$ were incubated for $6 \mathrm{~h}$ with CHO cells. $12 \mathrm{nM} \mathrm{CT}$ is used as positive control. At the end of the incubation, cells were analyzed with a light microscope. 


\subsection{Quantification and Characterization of Fluorescent Exosomes Containing CT Demonstrate the CTA Subunit Inclusion}

To better define the role of exosomes as a carrier of $\mathrm{CT}$, we applied a method we have developed based on the production of metabolically labeled fluorescent exo (F-exo), by using the fatty acid analogue BODIPY $^{\mathrm{TM}}$ FL C $_{16}$ (4,4-Difluoro-5,7-Dimethyl-4-Bora-3a,4a-Diaza-s-Indacene-3-hexadecanoic Acid) [15]. Upon incubation with cells, BODIPY C16 enters the cellular lipid pathway and is transformed mostly into phospholipids that will become part of the F-exo lipid bilayer. Accordingly, we labeled Me665 cells for $5 \mathrm{~h}$ with BODIPY C16, followed (or not) by the addition of $12 \mathrm{nM} \mathrm{CT}$ for $2 \mathrm{~h}$, and incubated for additional $24 \mathrm{~h}$ in fresh media. F-exo were purified by differential centrifugation from conditioned media, and F-exo were analyzed by FACS. As shown in Figure 2A, both F-exo and F-exo CT appear as discrete, countable fluorescent populations, comparable in size and fluorescence intensity.
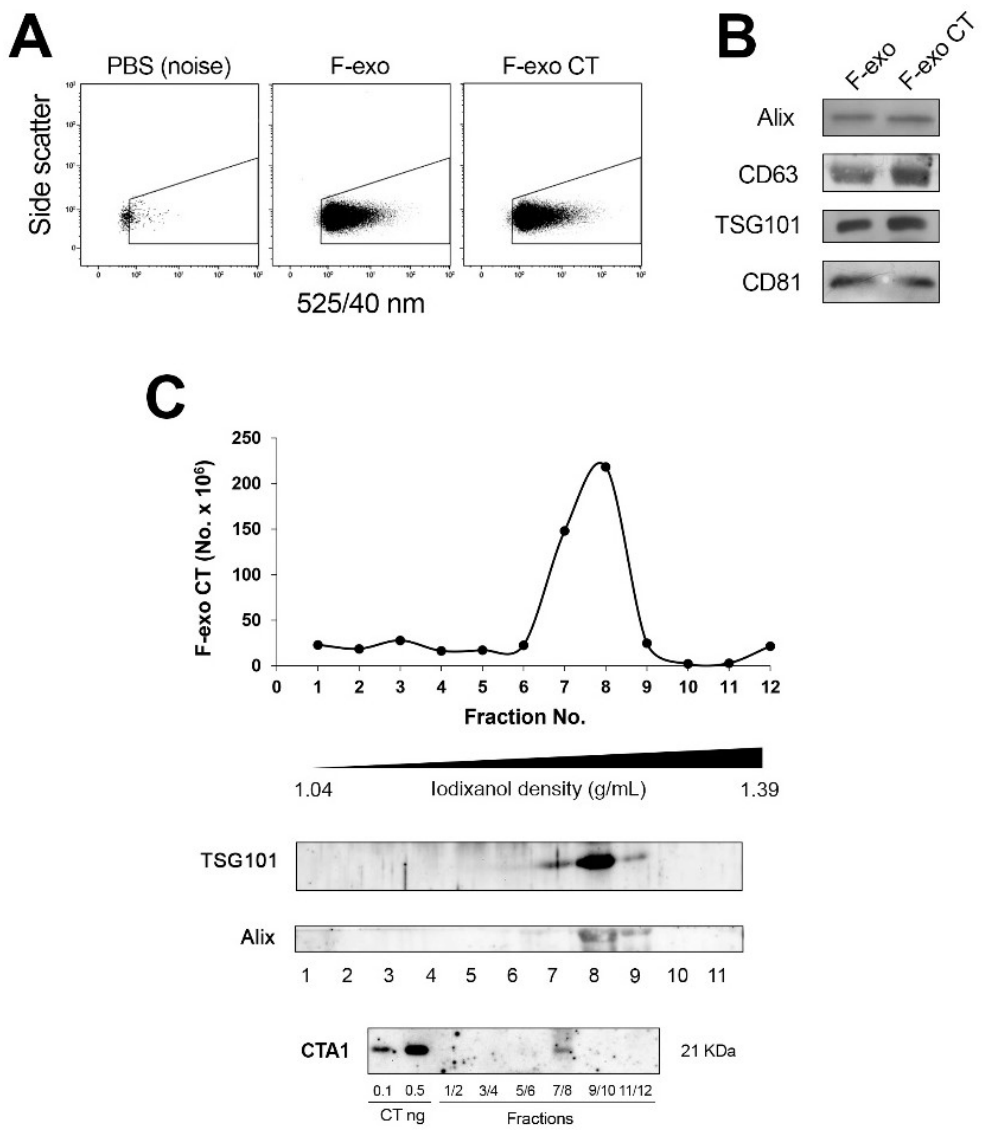

Figure 2. Characterization and distribution of F-exo CT purified from Me665 cells on an iodixanol gradient. (A) FACS analysis of F-exo and F-exo CT deriving from Me665 cells incubated with or without 12 nM CT. To design the F-exo region above instrument background noise only phosphate buffered saline (PBS) was acquired. Note that no events were registered in this region; (B) Western blot analysis of F-exo and F-exo CT probed with antibodies against exosome markers Alix, Tumor Susceptibility Gene (TSG)101, CD63 and CD81; (C) The F-exo CT sample was loaded at the bottom of an iodixanol discontinuous density gradient and subjected to ultracentrifugation for $18 \mathrm{~h}$. The resulting fractions (1-12) with increasing density were analyzed for vesicles number by FACS and for the presence of exosome markers TSG101 and ALIX by Western blotting. The fluorescent peak displays a density ranging from 1.085 to 1.142 . Fractions 1-2, 3-4, 5-6, 7-8, 9-10, 11-12 were pooled, trichloroacetic acid (TCA) precipitated and analyzed by western blot after running a Sodium dodecyl sulfate polyacrylamide gel electrophoresis (SDS-PAGE) in reducing condition for the presence of CTA subunit. For Western blot, an equal volume of each sample was analyzed. 
Equal numbers of F-exo and F-exo CT were characterized by Western blot analysis for the presence of typical exo markers (Alix, TSG101, CD63 and CD81). Figure 2B shows that these markers are equally present in both F-exo and F-exo CT preparations, showing that CT does not alter the protein profile of the exosomes. To further characterize the F-exo population, we loaded F-exo CT onto a continuous iodixanol gradient to allow optimal separation of EV subtypes of different buoyant densities, and the gradient fractions were analyzed for vesicle number by FACS (Figure 2C). F-exo CT separated in a discrete peak of density range $1.085-1.142 \mathrm{~g} / \mathrm{mL}$, as measured by refractometry, in accordance with the previously reported density of exosomes [8]. Western blot analysis of gradient fractions showed that the exosomal markers TSG101 and Alix colocalized with the fluorescent peak (fractions 7-8), further indicating that the F-exo population corresponds to bona fide exosomes. The gradient fractions were also probed by western blot for the presence of CT with a monoclonal antibody against CTA. Results show that CTA1 was present in the pooled 7-8 fractions, corresponding to the F-exo fluorescent peak (Figure 2C). This shows the occurrence of the enzymatic moiety of $\mathrm{CT}$ in the exosomes.

\subsection{Intracellular Distribution of CT in Me665 Cells}

To visualize the intracellular trafficking of CT, we first pulsed Me665 cells with BODIPY C16 for $5 \mathrm{~h}$ to metabolically label membrane sub-compartments. Cells were then treated with $12 \mathrm{nM} \mathrm{CT}$ for $20 \mathrm{~min}$ on ice to allow CT binding to the plasma membrane. The cells were then washed (T0) and incubated with fresh medium for a further $24 \mathrm{~h}$ at $37^{\circ} \mathrm{C}$ (T24). Following fixation, cells were analyzed by confocal microscopy. As shown in Figure 3A, at T0, CT clearly labeled only the plasma membrane and no co-localization with BODIPY C16-labeled internal membrane compartments was observed. Notably, lipid associated fluorescence was not present at the plasma membrane, further suggesting that F-exo do not derive from plasma membrane direct budding. At T24, CT staining was diffused in the cytoplasm, as well as in discrete spots, and co-localized with lipid-based fluorescence, suggesting the presence of $\mathrm{CT}$ in late endosomal/MVB compartments.

To further characterize the subcellular localization of $\mathrm{CT}$, we performed confocal microscopy of CT-treated cells (T24) using antibodies against BMP, a lipid whose occurrence is specific to the late endosomal MVB/lysosomal membrane tracking pathway [18], and TSG101, a component of ESCRT that functions in the early stage of MVBs formation $[19,20]$. Figure 3B shows that CT co-localized with both BMP and TSG101 (inset), providing additional proof of the intersection of the CT trafficking pathway with the exosome biogenesis pathway.

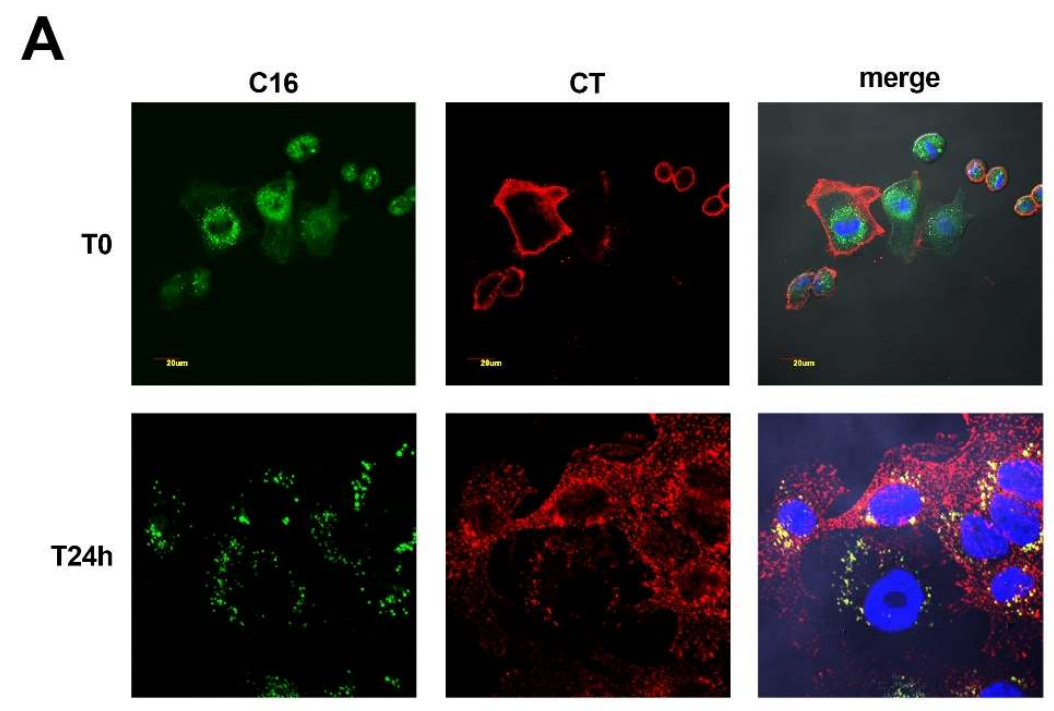

Figure 3. Cont. 
B

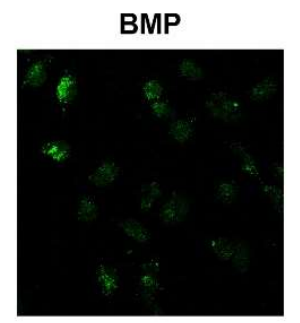

TSG101

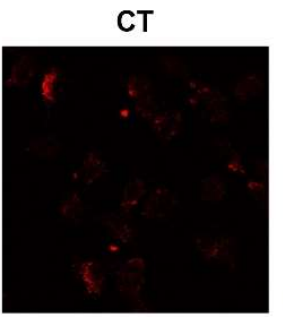

CT
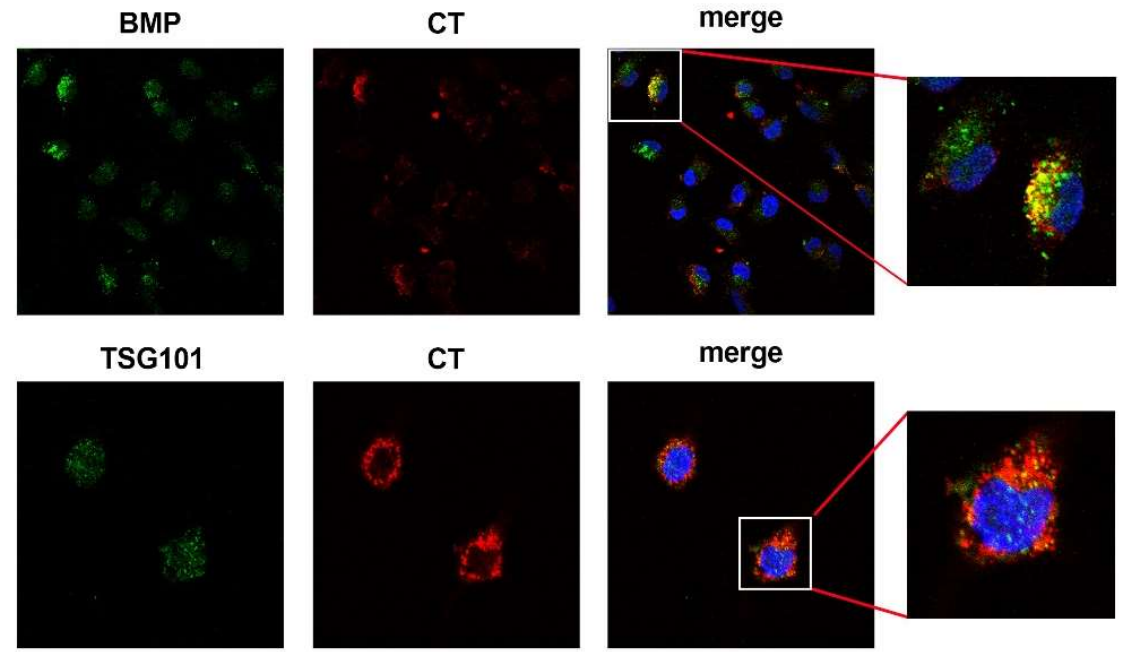

merge

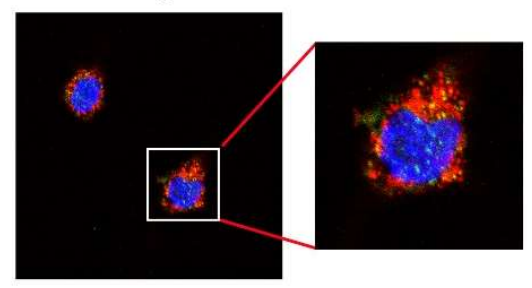

Figure 3. Intracellular distribution of CT in Me665 cells labeled with BODIPY C16. (A) Confocal microscopy analysis of Me665cells metabolically labeled with BODIPY C16, treated with $12 \mathrm{nM}$ $\mathrm{CT}$ for $20 \mathrm{~min}$ on ice, and then incubated with CT-free medium for $24 \mathrm{~h}$ at $37{ }^{\circ} \mathrm{C}$. Images were taken at T0 and T24 h after the removal of CT. BODIPY C16 is represented in green and CT in red; (B) Cells, immunolabeled for BMP or TSG101 (green) and for CT (red) show colocalization of both with CT, as evidenced in insets. Bar represents $20 \mu \mathrm{m}$. For all images DAPI staining was used for nuclear localization.

\subsection{CTA Active Subunit Is Retrieved in Association HSP90/PDI with Respect to F-exo Biogenesis}

With the aim of tracking F-exo CT biogenesis in Me665 cells, we pulsed cells with BODIPY C16 for $5 \mathrm{~h}$ to allow metabolic labeling of membrane compartments, including MVB before CT addition, for a further $2 \mathrm{~h}$. Cells were then chased in fresh media for $1 \mathrm{~h}$, before the media was removed and fresh media added for time intervals of up to $24 \mathrm{~h}$. Exosome purification was performed on each of the conditioned media samples, to determine the kinetics of F-exo release into the extracellular medium (Figure 4A).

From as early as $1 \mathrm{~h}$, cells secrete a discrete population of F-exo that can be FACS counted.

F-exo CT collected at $1 \mathrm{~h}$ and successively, after the addition of fresh medium, at $24 \mathrm{~h}\left(3 \times 10^{7}\right.$ exo for each time point), were run on SDS-PAGE and immunoblotted with antibodies against CTA and CTB subunits. Figure 4B shows that CTA was present in F-exo CT at both time points, and was more evident at $1 \mathrm{~h}$ than at $24 \mathrm{~h}$, presumably because the reservoir of $\mathrm{CT}$ in the cells was slowly decreasing over time. In addition, the blots were probed for the presence of HSP90 and protein disulfide isomerase (PDI), proteins that are required for protein translocation of the unfolded CTA1 domain from the ER lumen to the cytosol [21]. Both HSP90 and PDI were present in the F-exo CT samples $1 \mathrm{~h}$ and $24 \mathrm{~h}$, indicating that exo may constitute a membrane translocation system that facilitates the spread of CT toxicity to other cells, since PDI has the ability to dissociate the active CTA1 from the holotoxin. To see if the native $21 \mathrm{kDa}$ CTA1 subunit was also present in the exosome vesicles, we loaded F-exo CT onto an SDS-PAGE gel in non-reducing conditions, prior to western blotting with an anti-CTA antibody. Figure $4 \mathrm{C}$ shows that both the $28 \mathrm{kDa}$ CTA (CTA1 + CTA2) and $21 \mathrm{kDa}$ CTA1 bands are visible. Finally, to assess the localization of CTA, we exposed F-exo CT to chymotrypsin digestion, with or without Triton X-100, assuming that the CT molecules enclosed within exo lumen would be protected from hydrolysis by the vesicle membrane (Figure 4D). Western blot analysis with an anti CTA monoclonal antibody showed that, in the absence of detergent, chymotrypsin degraded a substantial fraction of exo-associated CTA. However, complete digestion was observed in the presence of Triton X-100 and 
chymotrypsin. These results show that a portion of the CTA component of the exosomes is present within the lumen of vesicles.
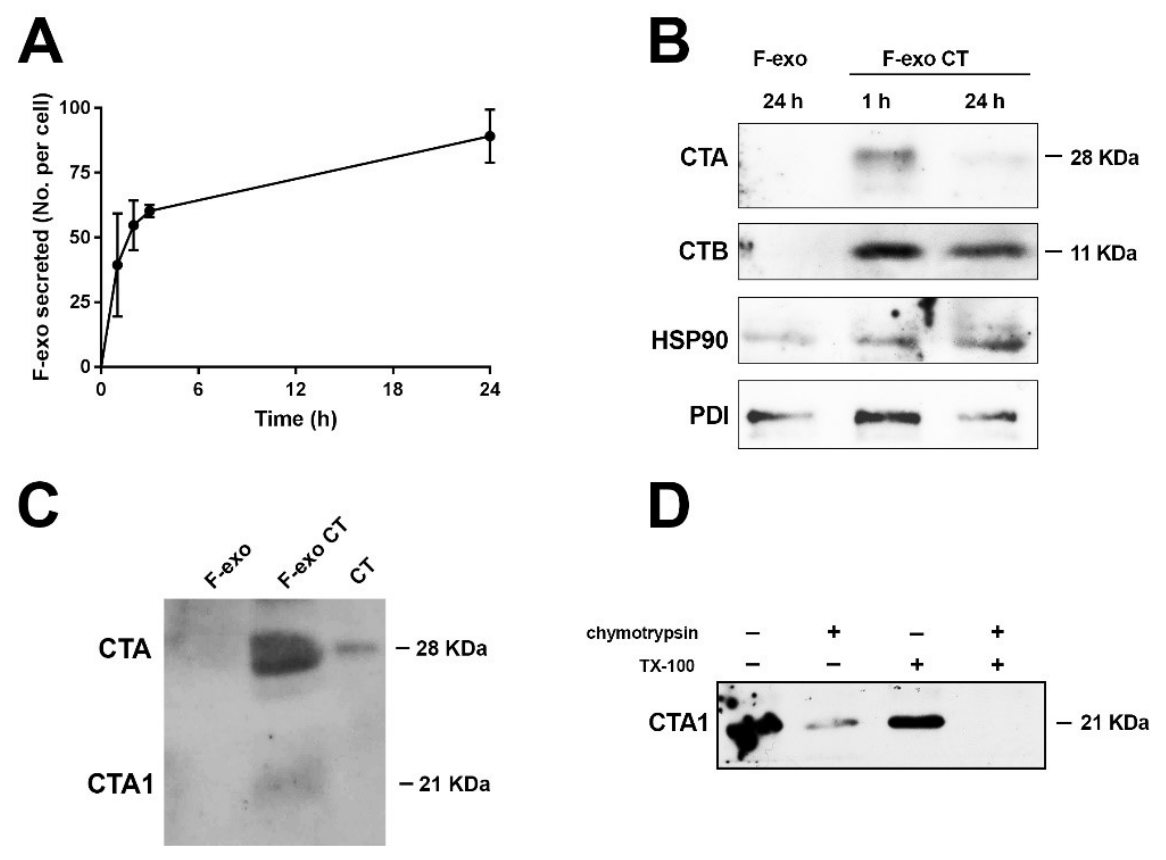

Figure 4. Exosome biogenesis and analysis of intra/extra localization of CT. (A) Me665 exosome biogenesis. Cells were pulsed with BODIPY C16 for $5 \mathrm{~h}$ for cell labeling, washed and complete medium was added. Cell conditioned medium was harvested at different time points for exosome recovery and quantification by FACS. Amount of exo secreted per cell is shown; (B) Western Blot analysis of F-exo CT recovered at $1 \mathrm{~h}$ and $24 \mathrm{~h}$ subtracted of the $1 \mathrm{~h}$ time point. The same number $\left(3 \times 10^{7}\right)$ of F-exo or F-exo CT were run on a non reducing SDS-PAGE gel, and immunoblotted for CTA and CTB subunits, HSP90 and PDI; (C) Western blot analysis of F-exo and F-exo CT $\left(6 \times 10^{7}\right)$ run in non-reducing conditions to show the presence of CTA1 and CTA1 + CTA2 subunits. The monoclonal antibody anti-CTA reveal the presence of both the $28 \mathrm{kDa}$ and the $21 \mathrm{kDa}$ subunits. $0.3 \mathrm{ng}$ of CT were used as positive control; (D) $16 \mu \mathrm{g}$ of exo CT were incubated with $1 \mu \mathrm{g}$ of chymotrypsin, in the absence or presence of $0.2 \%$ Triton $\mathrm{X}-100$. Samples were then loaded on SDS-PAGE gel in reducing conditions before western blot analysis using a monoclonal antibody anti-CTA.

\subsection{Functional Activation of Adenylate Cyclase Following F-exo Direct Transfer to Cells}

Exosomes play a central role in cell-to-cell communication by interaction with target cells. The influence of exosome based $\mathrm{CT}$ on $\mathrm{CHO}$ cell morphology indicates that the $\mathrm{CT}$ is activating intracellular adenylate kinase of target cells. To induce such a functional modification of the adenylate cyclase, giving rise to increased levels of cAMP [22], it is likely that exo containing CT must first be endocytosed by recipient cells. To test this hypothesis, we incubated $\mathrm{CHO}$ and Me665 cells with homologous F-exo containing CT, or with F-exo derived from control (non CT-exposed) cells. Internalization of F-exo was evaluated by confocal microscopy (Figure 5A).

When $\mathrm{CHO}$ cells were treated with control F-exo, uptake of the exosome-associated fluorescence was clearly visible, although no morphological changes were observed. In contrast, treatment with F-exo CT induced the characteristic elongated shape (Figure 5A upper panel). Internalization of F-exo fluorescence could also be observed in Me665 cells, both by confocal microscopy (Figure 5A lower panel) or by direct assessment of fluorescence transfer by FACS analysis (Figure 5B). Finally, to directly assess the activation of adenylate cyclase in Me665 cells, we treated cells with control F-exo, or F-exo $\mathrm{CT}$ for $4 \mathrm{~h}$ and measured cAMP levels by using a cAMP assay kit. Replicate cells were directly exposed to $\mathrm{CT}$ as a positive control, or were treated with neither CT nor exosomes. Exposure of cells to CT 
$(0.2 \mathrm{ng} / \mathrm{mL})$ or to F-exo CT increased cAMP levels to comparable extents, while control F-exo treatment did not affect cellular cAMP levels. By using fluorescence calibration beads, we could estimate that by incubating 285 exo per cell in the experiment in Figure 5C, only 35 exo per cell were taken up by recipient cells (means of 4 experiments, S.D. $=6.5$ ). These data show that CT carried by exosomes is biologically active in target cells.
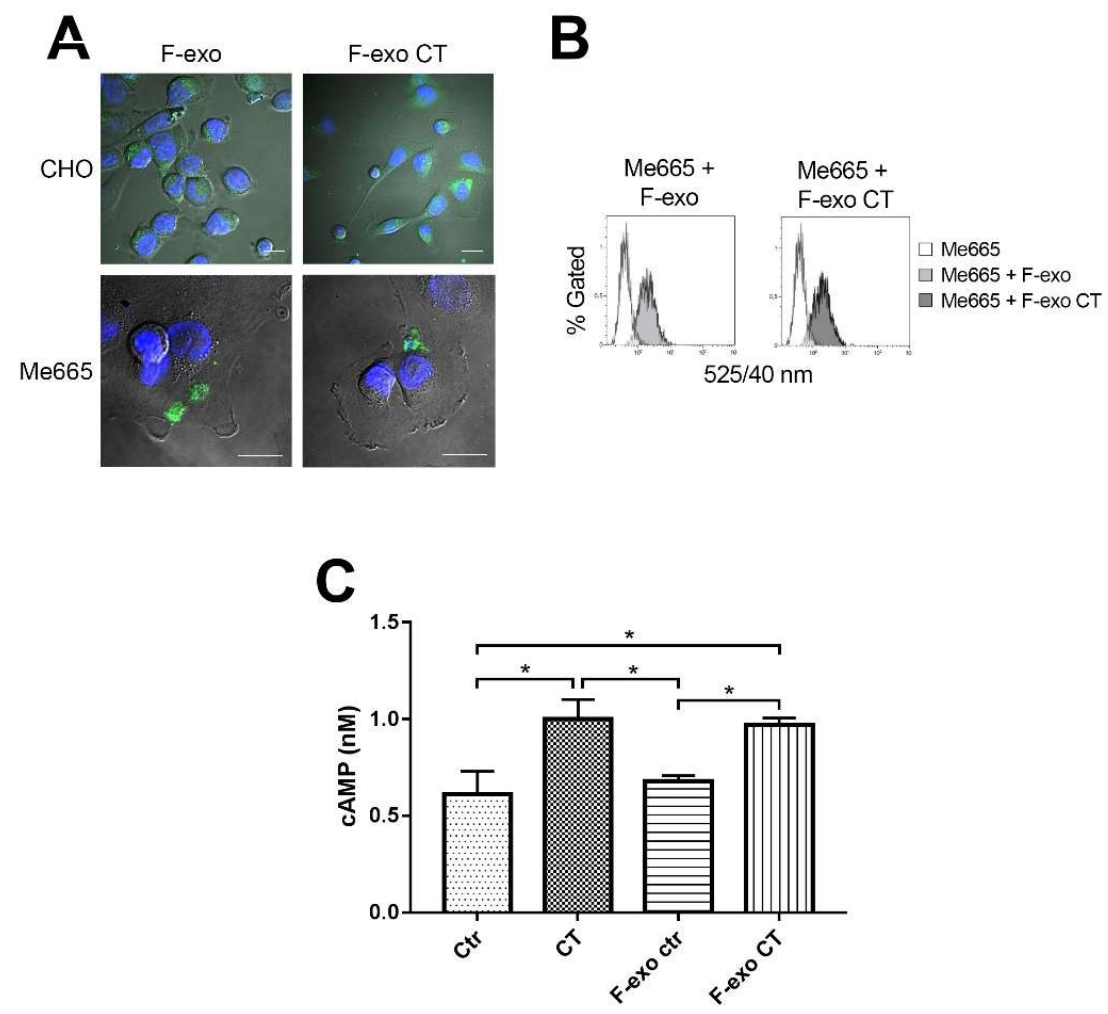

Figure 5. F-exo transfer to cells induces increase of cellular cAMP. (A) Confocal fluorescence microscopy images of F-exo and F-exo CT transfer on $\mathrm{CHO}$ and Me665 cells. $2 \times 10^{8}$ fluorescent exosomes were incubated with $4 \times 10^{4} \mathrm{CHO}$ and Me665 cells for $4 \mathrm{~h}$ at $37^{\circ} \mathrm{C}$. Cells were then fixed and analysed; Scale bars represent $20 \mu \mathrm{m}$; (B) FACS analysis of F-exo and F-exo CT transfer on target cells. $4 \times 10^{4}$ cells were incubated with $1.5 \times 10^{7} \mathrm{~F}$-exo or F-exo $\mathrm{CT}$ for $4 \mathrm{~h}$ at $37^{\circ} \mathrm{C}$. At the end of the incubation cells were FACS analysed. The increase in cell fluorescence demonstrate exo transfer to cells; (C) cAMP assay of Me665 cells treated with F-exo. $2 \times 10^{5}$ cells were incubated with $5.7 \times 10^{7}$ F-exo, F-exo CT or $0.2 \mathrm{ng} / \mathrm{mL} \mathrm{CT}$ for $4 \mathrm{~h}$ at $37^{\circ} \mathrm{C}$. The graph shows the intracellular cAMP production of cells. ${ }^{*} p<0.05$ Values are means \pm S.D. $(n=3)$.

\section{Discussion}

Cholera toxin cell entry and intracellular trafficking has been widely studied. There is a common consensus that GM1-based binding of CT is followed by retrograde vesicular trafficking from the plasma membrane through early endosomes, the Trans-Golgi Network, and the endoplasmic reticulum (ER), before the active CTA1 subunit reaches the cytosol and its final specific substrate [23]. This latter step appears to require interactions with host cell accessory proteins, such as the chaperone Hsp90 and the protein-folding helper enzyme PDI, which allow membrane translocation of the unfolded CTA1 domain $[4,24,25]$. Once in the cytosol, CTA1 recovers the active conformation required for ADP-ribosylation of its target, the $\alpha$ subunit of the heterotrimeric $G$ protein $(G s \alpha)[26,27]$ activates adenylate cyclase, giving rise to increased levels of cellular cyclic AMP (cAMP) [28]. It is well known that CTB binding and cross-linking of five GM1 molecules serve to promote the function of lipid rafts in toxin trafficking; in fact, lowering the expression of GM1 or cholesterol can prevent 
CT endocytosis [29-31]. However, the specific intracellular trafficking pathway of GM1 is not well understood. Despite the fact that many aspects of the CT-GM1 retrograde trafficking pathway from PM to ER have been elucidated, when three major pathways of CT entry (i.e., caveolin, clathrin, or Arf6 dependent) are inhibited, no significant reduction in toxicity is observed, and therefore, one or more as yet unknown pathways have been hypothesized to contribute [32]. A retracing study of CT intoxicating retrograde pathways carried out using subsets of GM1 (specified by saturated or unsaturated fluorescent-labeled ceramide chains) showed that CT bound to saturated GM1, in contrast to that bound to the unsaturated complex forms, is directed towards late endosome compartments (including MVBs that contain exosomes) rather than towards the classical Golgi/ER pathway [33]. Accordingly, it has been reported that GM1 gangliosides localize in the membrane of exosomes [34]. Notably, previous studies showed that caveolae and lipid raft associated proteins and lipids can take part in biogenesis and secretion of cell-derived exosomes [16,35,36].

In this study, we reported for the first time that CT can be propagated via EVs in a biologically active form, and that CT persists in cells long after treatment with the toxin. Accordingly, EVs collected from cells up to $72 \mathrm{~h}$ after their exposure to CT, still contain biologically active CT. Cells release different types of EVs, not all of endo/lysosomal origin, such as ectosomes that directly bud from the plasma membrane [18]. To distinguish among different types of vesicles, we applied a novel methodology that was developed in our lab [15] for the metabolic labeling of exosomes. BODIPY C16, a fluorescent phospholipid precursor, is efficiently incorporated into cells, and once metabolized in the ER, takes the endosomal/MVB route to become an integral part of the exosome membrane. Notably, as shown in Figure 3A, lipid associated fluorescence seemed completely absent from the plasma membrane, whereby we could exclude its involvement in fluorescent ectosomes generation.

Fluorescent exo secreted in the extracellular medium can be purified and readily counted. It has also to be noted that the final purified vesicular pellet contains much less vesicles than those present in the initial medium. In fact, our labeling technique allowed us to determine that a considerable amount of fluorescent exosomes remain suspended or associated with different kind of debris and serum macromolecular components in the supernatant and in the low speed pellets. We show here that CTA is associated with a discrete population of fluorescent exo that express typical exo markers, indicating that $\mathrm{CT}$ is a bona fide component of exosomes (Figure 2). Furthermore, this methodology allowed us to highlight intracellular membrane compartments that intersect with the trafficking pathway of internalized CT (Figure 3A). Specifically, colocalization of CT with MVB-specific markers was observed in the endolysosomal compartment (Figure 3B). This suggests that exosomes, in addition of being a means of transport, may represent a kind of CT-repository within the MVBs, allowing CT to be protected from intracellular degradation, and allowing for long-term activity. Despite the fact that in vitro uptake of exosomes is a complex mechanism which has not yet been clarified, we also demonstrate that there is a strict relation between the cellular uptake of CT containing exo and functional alterations in recipient cells highlighted in $\mathrm{CHO}$ cells by the morphological changes and in Me665 cells by direct increase of cellular cAMP levels. A final consideration is that in a physiological setting, there may be many other factors that can influence the efficiency of cellular uptake, such as time of exposure, or more importantly, the vicinity between intoxicated cell secreting exosomes and recipient cells.

F-exo biogenesis studies allowed us to monitor CT secretion over time, highlighting an early release of F-exo containing CT (at 1 h). At later times (24 h), CT was still present in F-exo, albeit in lower amounts, showing that the bulk of $\mathrm{CT}$ associated with exo is released soon after toxin internalization. Interestingly, the host cell chaperone HSP90, an established exosomal marker [37], and protein-helper enzyme PDI were both clearly present in the exosomes, together with the CT subunits (Figure 4B). Furthermore, CTA was present in exo both in the active reduced form, CTA1 (21 kDa), or as the inactive disulfide linked CTA1 and CTA2 (28 kDa) form. Chymotrypsin digestion of F-exo containing CT revealed that the CTA subunit is distributed both outside and inside of exosome membranes. Based on our results, an appealing speculation is that CTA associated with exo may derive from two distinct 
intracellular routes: upon cell entry, some CT molecules may follow the long chain saturated GM1 pathway [33], presumably along with Cav-1, leading the CT holotoxin direct to the late endosomal compartment/MVB before being secreted; on the other hand, CTA1 in exosomes may originate from the canonical ER retrograde pathway, where, by the action of HSP90 and PDI, CTA1 is translocated to the cytosol and taken up during exo formation by intraluminal vesicles.

In conclusion, starting from the more general hypothesis which suggests that exosomes are vehicles that can influence cell homeostasis, we found that CT could exploit the exosome biogenesis pathway to spread its action from a single cell to an entire cell population. In light of our results, we may hypothesize that $V$. cholerae fast dynamic mechanism of intestinal infection relies on the effect of the cell-to-cell transmission of CT containing exo. In fact, in normal healthy adults, primary symptoms of cholera disease appear from half a day to five days after ingestion of at least 100 million bacteria, of which only few thousands survive the harsh acidic conditions of the stomach. Afterwards, only a small handful of bacteria penetrate the thick mucus wall to reach the $V$. cholerae natural setting, the small intestine, where they take hold and release CT [38]. We reason that the rapidity by which infection propagates among lining intestinal epithelia may be caused by the horizontal transfer of exosomal payloads that include active CTA subunits. This latter readily interacts with the host cell mechanisms to pump chloride ions into the small intestine, which can pull up to six liters of water per day through the intestinal cells through osmosis, eventually creating a thriving environment for bacteria exponential growth. Thus, our study suggests potentially important roles for exosomes in cholera pathogenesis, and in the dynamics of this infectious disease, given that these vesicles seem to preserve and protect the toxin, and facilitate its transfer from cell to cell.

\section{Materials and Methods}

\subsection{Cell Culture}

The Human melanoma cell line, Me665/1 (Me665), stabilized from surgical specimen obtained from metastatic lesions at Istituto Nazionale Tumori (Milan, Italy) and CHO (Chinese hamster ovary, American Type Culture Collection, Rockville, MD, USA) cell line commercially available, were grown in Dulbecco's modified Eagle's medium (DMEM) (EuroClone, S.p.A. Milan, Italy) supplemented with $10 \%$ fetal bovine serum (FBS) (Biological Industries, Kibbutz Beit Haemek, Israel), $5 \mathrm{mM}$ L-glutamine, penicillin (100 units $/ \mathrm{mL}$ ), and streptomycin $(100 \mu \mathrm{g} / \mathrm{mL})$ (complete media, EuroClone S.p.A. Milan, Italy) at $37^{\circ} \mathrm{C}$ in a humidified $5 \% \mathrm{CO}_{2}$ atmosphere.

\subsection{Isolation of EVs from $\mathrm{CHO}$ and Me665 Cell Culture Supernatants}

For isolation of EVs, subconfluent monolayers of $\mathrm{CHO}$ and Me665 cells in exponential growth were incubated in DMEM supplemented with $0.3 \%$ FBS with or without $12 \mathrm{nMCT}$, and purified from culture filtrates of Vibrio Cholerae 569 B, serotype Inaba, as described by [39]. After 2 h of CT treatment, control and CT treated cells were washed in PBS and further cultured in fresh DMEM medium for $24 \mathrm{~h}$ before collection of medium for EVs isolation. EVs were isolated from the culture supernatants of treated and untreated cells by sequential centrifugations, as previously described [15,40], with some modifications. Briefly, culture supernatant was centrifuged at $2000 \times \mathrm{g}$ for $20 \mathrm{~min}$ at $4{ }^{\circ} \mathrm{C}$ to pellet cells debris. Supernatants were transferred to new tubes and centrifuged in a SW41Ti rotor (Beckman, Coulter, Milan, Italy) at $10,000 \times g$ for $20 \mathrm{~min}$ at $4{ }^{\circ} \mathrm{C}$, and finally ultracentrifuged at $100,000 \times g$ for $3 \mathrm{~h}$. Pellets were washed in PBS and ultracentrifuged at the same speed for $3 \mathrm{~h}$ to further remove any residual CT still present in the exo preparation, since, along with vesicles, some free intact CT is also recycled to the extracellular milieu, and can be found in the supernatant after ultracentrifugation.

\subsection{Morphological Analysis of CHO Cells after CT, EV and EV-CT Treatment}

Exponentially growing $\mathrm{CHO}$ cells were harvested, transferred to 12 -well plates $\left(2 \times 10^{4}\right.$ cells $/$ well $)$, and DMEM supplemented with $0.3 \%$ FBS. Cells were incubated with or without $12 \mathrm{nM} \mathrm{CT}$, or with EV 
and EV-CT (prepared as described above). After $6 \mathrm{~h}$ incubation, cells were inspected microscopically to analyze the morphological changes.

\subsection{Dot Blot and Western Blot Analysis}

Cell pellets were lysed in $20 \mathrm{mM}$ Tris, pH 7.4, $150 \mathrm{mM} \mathrm{NaCl}, 1 \%$ Triton X-100, 2 mM EDTA with a Protease Inhibitor Cocktail (Roche Applied Sciences, Mannheim, Germany) for 20 min on ice, and then centrifuged at $2000 \times g$ for $10 \mathrm{~min}$. The pellet was discarded and supernatant was kept for further analysis. Protein concentration was measured using the BCA assay (Thermo Fisher Scientific, Waltham, MA, USA). The presence of GM1 ganglioside in cell lysates was assessed by the dot blot assay using horseradish peroxidase (HRP)-conjugated CTB subunit, and revealed with an ECL detection kit (Pierce $^{\mathrm{TM}}$ ECL Western Blotting Substrate, Thermo Fisher Scientific). Cell lysates ( $\left.40 \mu \mathrm{g}\right)$ were boiled and spotted onto a nitrocellulose membrane blocked using 5\% Blotting Grade non-fat dry milk in a TBS-Tween (TBST) buffer (10 mM Tris- $\mathrm{HCl}$ (pH 8.0), $150 \mathrm{mM} \mathrm{NaCl}, 0.1 \%$ Tween 20) for $45 \mathrm{~min}$ at room temperature (RT), followed by incubation with HRP-CTB dissolved in TBST buffer (1:400) for $1 \mathrm{~h}$ at RT. The reactivity was detected using an ECL detection kit (Pierce). For Western Blot analysis, exosome preparations were lysed in Laemmli sample buffer, boiled, and loaded onto 10\% or $14 \%$ SDS-PAGE gels under reducing or non-reducing conditions. Proteins were blotted onto a nitrocellulose membrane, and blocked using 5\% Blotting Grade non-fat dry milk in TBS-Tween (TBST) buffer (10 mM Tris-HCl (pH 8.0), $150 \mathrm{mM} \mathrm{NaCl}, 0.1 \%$ Tween 20) for $1 \mathrm{~h}$ at RT followed by incubation with primary antibodies. The following primary antibodies were used: mouse anti-Cholera Toxin A (Clone 2H9) (Immunology Consultants Laboratory, Inc., Portland, OR, USA) 1:500 and rabbit polyclonal Anti-Cholera toxin (Sigma Immuno Chemicals, St. Louis, MO, USA) 1:1000; rabbit anti-Caveolin-1 (N-20) (Santa Cruz Biotechnology, Dallas, TX, USA) 1:1000; rabbit anti-Protein Disulfide Isomerase Polyclonal Antibody (Stressgen Biotechnologies Corporation, San Diego, CA, USA) 1:1000; rabbit anti-HSP90 $\alpha / \beta$ (H-114) (Santa Cruz Biotechnology) 1:1000 dissolved in TBS-Tween (TBST) buffer for $1 \mathrm{~h}$ at RT; mouse anti-Alix (3A9) (Thermo Scientific) 1:1000, rabbit anti-CD63 (SBI) 1:1000, mouse anti-CD81 1:1000, mouse anti-TSG101 (GeneTex, Inc., Irvine, CA, USA) 1:1000 dissolved in 0.25\% Blotting Grade non-fat dry milk in TBST overnight at $4{ }^{\circ} \mathrm{C}$. After washing with TBST, filters were incubated with appropriate horseradish peroxidase-conjugated secondary antibodies (Bio-Rad, Hercules, CA, USA) for $1 \mathrm{~h}$ at RT, and immunoreactivity was revealed by using an ECL detection kit (Pierce).

\subsection{Generation and Quantification of F-exo}

F-exo were purified and quantified as previously described [15]. Briefly, melanoma cells Me665 $\left(8 \times 10^{5}\right)$ were incubated with $7 \mu \mathrm{M}$ BODIPY FL C16 (4,4-difluoro-5,7-dimethyl-4-bora-3a,4a-diaza-sindacene-3-hexadecanoic acid) (BODIPY C16) (Life Technologies, Carlsbad, CA, USA) for $5 \mathrm{~h}$ at $37^{\circ} \mathrm{C}$ in DMEM supplemented with $0.3 \%$ FBS. Excess probe was removed by washing cells twice with PBS. Subsequently, cells were incubated with or without $12 \mathrm{nM} \mathrm{CT}$ in DMEM supplemented with $0.3 \%$ FBS for $2 \mathrm{~h}$ at $37^{\circ} \mathrm{C}$, and washed twice with PBS to remove excess CT and further incubated for different times in complete media. Conditioned medium was centrifuged at $2000 \times g$ for $20 \mathrm{~min}$ to remove cells and cell debris. The pellet was discarded and the supernatant centrifuged at $10,000 \times g$ $(10 \mathrm{~K})$ to remove microvesicles. F-exo and F-exo CT were isolated by ultracentrifugation of the $10 \mathrm{~K}$ supernatant at $100,000 \times g(100 \mathrm{~K})$ for $3 \mathrm{~h}$, and the resulting pellet washed in PBS for $3 \mathrm{~h}$ at $100,000 \times g$. All ultracentrifugation steps were performed at $4{ }^{\circ} \mathrm{C}$ using a SW41 Ti rotor (Beckman Coulter, Brea, CA, USA). The final pellet was resuspended in PBS and quantified by FACS (FC Gallios Flow Cytometer and Kaluza Software-Beckman Coulter). To set the instrument, fluorescent beads (525/540 nm FL1) ranging in size from 0.1 to $0.5 \mu \mathrm{m}$ were analyzed. Flow count fluorospheres, used to determine exosome number, were resuspended in PBS with F-exo and F-exo CT, and the instrument was set to fix the stopping gate on 2000 flow count fluorospheres. For further details, refer to [15]. For F-exo biogenesis studies, F-exo CT were collected at different time points (1-24 h) after $2 \mathrm{~h}$ of $\mathrm{CT}$ incubation. 


\subsection{Iodixanol/OptiPrep ${ }^{T M}$ Gradient Separation}

A discontinuous iodixanol gradient was used for further exosome purification, as described by several authors [41]. Solutions of $10 \%, 30 \%$ and $40 \%$ iodixanol were made up by mixing appropriate amounts of homogenization buffer (HM solution: 0.25 M sucrose, $1 \mathrm{mM}$ EDTA, $10 \mathrm{mM}$ Tris-HCL $\mathrm{pH}=7.4$ ) and an iodixanol working solution. This working solution was prepared by combining a working solution buffer $(0.25 \mathrm{M}$ sucrose, $6 \mathrm{mM}$ EDTA, $60 \mathrm{mM}$ Tris-HCL pH =7.4) and a stock solution of OptiPrep ${ }^{\mathrm{TM}}$ (60\% $w / v$ aqueous iodixanol solution, Sigma-Aldrich, Saint Louis, MS, USA). The gradient was formed by layering $1 \mathrm{~mL}$ of $60 \%$ with $0.260 \mathrm{~mL}$ sample, $0.5 \mathrm{~mL} 40 \%, 0.5 \mathrm{~mL} 30 \%$ and $1.8 \mathrm{~mL}$ of $10 \%$ solutions on top in a $4.5 \mathrm{~mL}$ open top polyallomer tube (Beckman Coulter, Brea, CA, USA). The gradient was then centrifuged for $18 \mathrm{~h}$ at $192,000 \times g$ at $4{ }^{\circ} \mathrm{C}$ (SW60 Ti rotor Beckman Coulter). Gradient fractions of $350 \mu \mathrm{L}$ were collected from the top of the gradient and analyzed by FACS for exosome count. Fractions were loaded on a SDS-PAGE gel for Western blotting analysis using antibodies directed against exosome markers TSG101 and Alix. For CT detection, gradient fractions were TCA precipitated. The refractive index of each fraction was assessed with a refractometer (Carl Zeiss, Oberkochen, Germany), and the relative density was calculated using the linear relationship between refractive index $(\eta)$ and the density $(\rho) \rho=$ A $\eta-B$.

\subsection{Chymotrypsin Treatment of exo}

To analyze the intra/extra localization of CT, exo CT $(16 \mu \mathrm{g})$ were incubated with or without $1 \mu \mathrm{g}$ of chymotrypsin, in the absence or presence of $0.2 \%$ Triton $\mathrm{X}-100$, at $37^{\circ} \mathrm{C}$ for $3 \mathrm{~h}$ at $\mathrm{pH} 7.8$. Digestion was stopped on ice with $5 \mu \mathrm{M}$ phenylmethanesulfonyl fluoride (PMSF). Samples were then mixed with Laemmli buffer, heated at $95{ }^{\circ} \mathrm{C}$ for $5 \mathrm{~min}$, and analyzed by SDS-PAGE and western blotting.

\section{8. cAMP Assay}

Freshly trypsinized cells were transferred to 6-well plates $\left(2 \times 10^{5}\right.$ cells/well $)$ and incubated overnight at $37^{\circ} \mathrm{C}$ in DMEM with $10 \%$ FBS to allow cell attachment. Plates were then washed with serum-free DMEM, and $1 \mathrm{~mL}$ of 1\% FBS DMEM containing $0.5 \mathrm{mM}$ 1-methyl-3-isobutylxantine (IBMX, Sigma-Aldrich, Saint Louis, MO, USA) was added for $30 \mathrm{~min}$. As control, IBMX treated cells were used. After incubation, $0.2 \mathrm{ng} / \mathrm{mL}$ of $\mathrm{CT}$ or a specific number $\left(5.7 \times 10^{7}\right)$ of F-exo and F-exo CT were added and plates were incubated at $37^{\circ} \mathrm{C}$ for $4 \mathrm{~h}$. Cells were washed in ice-cold PBS, and cAMP assay was performed, according to manufacturer's instructions (Cyclic AMP XP Assay kit, Cell Signaling Technology, Danvers, MA, USA).

\subsection{Confocal Microscopy}

To analyze the intracellular localization of CT, Me665cells $\left(4 \times 10^{4}\right)$ were cultured on 24-well plates containing coverslips until $60-70 \%$ of confluency. Cells were incubated at $37{ }^{\circ} \mathrm{C}$ with or without $7 \mu \mathrm{M}$ BODIPY C16 for $4 \mathrm{~h}$. $12 \mathrm{nM} \mathrm{CT}$ was added for $20 \mathrm{~min}$ on ice (T0), and cells were then incubated at $37{ }^{\circ} \mathrm{C}$ for $24 \mathrm{~h}$ (T24). Cells were fixed with $3 \%$ paraformaldehyde (PFA) for $20 \mathrm{~min}$ at RT and permeabilized with $0.05 \%$ saponin. The primary antibodies used were: rabbit polyclonal anti-Cholera toxin (Sigma-Aldrich), mouse anti-TSG101 (GeneTex, Hsinchu, Taiwan), and mouse anti-LBPA/BMP (6C4) (Echelon Corporation, San Jose, CA, USA). AlexaFluor647-conjugated and AlexaFluor488-conjugated goat anti mouse or anti rabbit (Life Technologies) was used as secondary antibody. Coverslips were mounted on the microscope slide with Vectashield antifade mounting medium containing DAPI (Vector Laboratories, Burlingame, CA, USA). Images were taken by a FV1000 confocal microscope (Olympus, Tokyo, Japan), using a (Olympus) planapo objective 60x oil A.N. 1.42. Excitation light was obtained by a Laser Dapi $408 \mathrm{~nm}$ for DAPI, an Argon Ion Laser (488 nm) for FITC (Alexa 488), and a Red Diode Laser (638 nm) for Alexa 647. DAPI emission was recorded from 415 to $485 \mathrm{~nm}$, FITC emission was recorded from 495 to $550 \mathrm{~nm}$, and Alexa 647 from 634 to $750 \mathrm{~nm}$. Images recorded have an optical thickness of $0.3 \mathrm{~mm}$. 


\subsection{F-exo and F-exo CT Transfer}

To evaluate the transfer on target cells, F-exo were incubated with cells in a 24-well plate in duplicate in $1 \mathrm{~mL}$ DMEM with $0.1 \%$ FBS and kept for $4 \mathrm{~h}$ at $37^{\circ} \mathrm{C}$ in $\mathrm{CO}_{2}$ incubator. The medium was then removed, and cells PBS washed, detached and subjected to FACS analysis for cell fluorescence, together with exo and a standard curve setup with Quantum ${ }^{\text {TM }}$ FITC-5 MESF (Molecules of Equivalent Soluble Fluorophores) (Bangs Laboratories, Inc., Fishers, IN, USA). The amount of transferred exo was estimated, as previously described [15]. Briefly, we transformed fluorescence data (arithmetic mean) of exo using the QuickCal analysis template provided with each Quantum ${ }^{\mathrm{TM}}$ MESF lot to determine MESF per Exo and cells. To transform MESF associated to cells in number of Exo transferred, we used the formula: transferred Exo number $=($ cell fluorescence $(\mathrm{MESF})-$ autofluorescence $(\mathrm{MESF})) / \mathrm{MESF}$ associated to a single Exo. For confocal microscopy, $4 \times 10^{4}$ cells were seeded on a sterilized coverslip and incubated with $2 \times 10^{8} \mathrm{~F}$-exo, or F-exo CT for $4 \mathrm{~h}$ at $37^{\circ} \mathrm{C}$ in DMEM with $0.1 \%$ FBS. At the end of incubation, the medium was removed, and the cells were washed with PBS and fixed with $3 \%$ PFA for analysis.

Author Contributions: C.Z., A.G. and A.F. performed the experiments and analyzed the data; S.P, A.P., K.F., Z.B., M.C., M.F. and L.P. performed the experiments; C.Z., M.L.F. and M.S. wrote the paper; M.L.F. and M.S. conceived and designed the experiments and analyzed the data.

Funding: This research was funded by the Ministry of Health, Italy, to M.S., grant n. RF2011-02347300.

Acknowledgments: We gratefully thank Tommaso Costa for helpful discussions and valuable advice and Catherine Nolan for critically reading the manuscript.

Conflicts of Interest: The authors declare no conflict of interest.

\section{References}

1. Chatterjee, D.; Chaudhuri, K. Association of cholera toxin with Vibrio choleraeouter membrane vesicles which are internalized by human intestinal epithelial cells. FEBS Lett. 2011, 585, 1357-1362. [CrossRef] [PubMed]

2. Gill, D.M.; Rappaport, R.S. Origin of the Enzymatically Active AI Fragment of Cholera Toxin. J. Infect. Dis. 1979, 139, 674-680. [CrossRef] [PubMed]

3. Sandvig, K.; Deurs, B.V. Transport of protein toxins into cells: Pathways used by ricin, cholera toxin and Shiga toxin. FEBS Lett. 2002, 529, 49-53. [CrossRef]

4. Sánchez, J.; Holmgren, J. Cholera toxin structure, gene regulation and pathophysiological and immunological aspects. Cell. Mol. Life Sci. 2008, 65, 1347-1360. [CrossRef] [PubMed]

5. Parton, R.G. Ultrastructural localization of gangliosides; GM1 is concentrated in caveolae. J. Histochem. Cytochem. 1994, 42, 155-166. [CrossRef] [PubMed]

6. Taylor, M.; Banerjee, T.; Navarro-Garcia, F.; Huerta, J.; Massey, S.; Burlingame, M.; Pande, A.H.; Tatulian, S.A.; Teter, K. A therapeutic chemical chaperone inhibits cholera intoxication and unfolding/translocation of the cholera toxin A1 subunit. PLoS ONE 2011, 6, e18825. [CrossRef] [PubMed]

7. Pang, H.; Le, P.U.; Nabi, I.R. Ganglioside GM1 levels are a determinant of the extent of caveolae/raftdependent endocytosis of cholera toxin to the Golgi apparatus. J. Cell Sci. 2004, 117, 1421. [CrossRef] [PubMed]

8. Colombo, M.; Raposo, G.; Théry, C. Biogenesis, Secretion, and Intercellular Interactions of Exosomes and Other Extracellular Vesicles. Annu. Rev. Cell Dev. Biol. 2014, 30, 255-289. [CrossRef] [PubMed]

9. Lo Cicero, A.; Stahl, P.D.; Raposo, G. Extracellular vesicles shuffling intercellular messages: For good or for bad. Curr. Opin. Cell Biol. 2015, 35, 69-77. [CrossRef] [PubMed]

10. El Andaloussi, S.; Lakhal, S.; Mäger, I.; Wood, M.J.A. Exosomes for targeted siRNA delivery across biological barriers. Adv. Drug Deliv. Rev. 2013, 65, 391-397. [CrossRef] [PubMed]

11. Mathivanan, S.; Ji, H.; Simpson, R.J. Exosomes: Extracellular organelles important in intercellular communication. J. Proteom. 2010, 73, 1907-1920. [CrossRef] [PubMed]

12. Simons, M.; Raposo, G. Exosomes-Vesicular carriers for intercellular communication. Curr. Opin. Cell Biol. 2009, 21, 575-581. [CrossRef] [PubMed] 
13. Abrami, L.; Brandi, L.; Moayeri, M.; Brown, M.J.; Krantz, B.A.; Leppla, S.H.; van der Goot, F.G. Hijacking multivesicular bodies enables long-term and exosome-mediated long-distance action of anthrax toxin. Cell Rep. 2013, 5, 986-996. [CrossRef] [PubMed]

14. Zhang, F.; Sun, S.; Feng, D.; Zhao, W.L.; Sui, S.F. A novel strategy for the invasive toxin: Hijacking exosome-mediated intercellular trafficking. Traffic 2009, 10, 411-424. [CrossRef] [PubMed]

15. Coscia, C.; Parolini, I.; Sanchez, M.; Biffoni, M.; Boussadia, Z.; Zanetti, C.; Fiani, M.L.; Sargiacomo, M. Generation, Quantification, and Tracing of Metabolically Labeled Fluorescent Exosomes. In Lentiviral Vectors and Exosomes as Gene and Protein Delivery Tools; Federico, M., Ed.; Springer: New York, NY, USA, 2016; pp. 217-235.

16. Felicetti, F.; Parolini, I.; Bottero, L.; Fecchi, K.; Errico, M.C.; Raggi, C.; Biffoni, M.; Spadaro, F.; Lisanti, M.P.; Sargiacomo, M.; et al. Caveolin-1 tumor-promoting role in human melanoma. Int. J. Cancer J. Int. Cancer 2009, 125, 1514-1522. [CrossRef] [PubMed]

17. Morinaga, N.; Kaihou, Y.; Vitale, N.; Moss, J.; Noda, M. Involvement of ADP-ribosylation Factor 1 in Cholera Toxin-induced Morphological Changes of Chinese Hamster Ovary Cells. J. Biol. Chem. 2001, 276, 22838-22843. [CrossRef] [PubMed]

18. Record, M.; Carayon, K.; Poirot, M.; Silvente-Poirot, S. Exosomes as new vesicular lipid transporters involved in cell-cell communication and various pathophysiologies. Biochim. Biophys. Acta 2014, 1841, 108-120. [CrossRef] [PubMed]

19. Tan, S.S.; Yin, Y.; Lee, T.; Lai, R.C.; Yeo, R.W.; Zhang, B.; Choo, A.; Lim, S.K. Therapeutic MSC exosomes are derived from lipid raft microdomains in the plasma membrane. J. Extracell. Vesicles 2013, 2, 22614. [CrossRef] [PubMed]

20. Lotvall, J.; Hill, A.F.; Hochberg, F.; Buzas, E.I.; Di Vizio, D.; Gardiner, C.; Gho, Y.S.; Kurochkin, I.V.; Mathivanan, S.; Quesenberry, P.; et al. Minimal experimental requirements for definition of extracellular vesicles and their functions: A position statement from the International Society for Extracellular Vesicles. J. Extracell. Vesicles 2014, 3, 26913. [CrossRef] [PubMed]

21. Ernst, K.; Schnell, L.; Barth, H. Host Cell Chaperones Hsp70/Hsp90 and Peptidyl-Prolyl Cis/Trans Isomerases Are Required for the Membrane Translocation of Bacterial ADP-Ribosylating Toxins. Curr. Top. Microbiol. Immunol. 2017, 406, 163-198. [PubMed]

22. Guerrant, R.L.; Brunton, L.L.; Schnaitman, T.C.; Rebhun, L.I.; Gilman, A.G. Cyclic adenosine monophosphate and alteration of Chinese hamster ovary cell morphology: A rapid, sensitive in vitro assay for the enterotoxins of Vibrio cholerae and Escherichia coli. Infect. Immun. 1974, 10, 320-327. [PubMed]

23. Wernick, N.L.B.; Chinnapen, D.J.F.; Cho, J.A.; Lencer, W.I. Cholera Toxin: An Intracellular Journey into the Cytosol by Way of the Endoplasmic Reticulum. Toxins 2010, 2, 310-325. [CrossRef] [PubMed]

24. Taylor, M.; Burress, H.; Banerjee, T.; Ray, S.; Curtis, D.; Tatulian, S.A.; Teter, K. Substrate-induced unfolding of protein disulfide isomerase displaces the cholera toxin A1 subunit from its holotoxin. PLoS Pathog. 2014, 10, e1003925. [CrossRef] [PubMed]

25. Taylor, M.; Navarro-Garcia, F.; Huerta, J.; Burress, H.; Massey, S.; Ireton, K.; Teter, K. Hsp90 Is Required for Transfer of the Cholera Toxin A1 Subunit from the Endoplasmic Reticulum to the Cytosol. J. Biol. Chem. 2010, 285, 31261-31267. [CrossRef] [PubMed]

26. Pande, A.H.; Scaglione, P.; Taylor, M.; Nemec, K.N.; Tuthill, S.; Moe, D.; Holmes, R.K.; Tatulian, S.A.; Teter, K. Conformational instability of the cholera toxin A1 polypeptide. J. Mol. Biol. 2007, 374, 1114-1128. [CrossRef] [PubMed]

27. Ampapathi, R.S.; Creath, A.L.; Lou, D.I.; Craft, J.W., Jr.; Blanke, S.R.; Legge, G.B. Order-disorder-order transitions mediate the activation of cholera toxin. J. Mol. Biol. 2008, 377, 748-760. [CrossRef] [PubMed]

28. Kaper, J.B.; Morris, J.G.; Levine, M.M. Cholera. Clin. Microbiol. Rev. 1995, 8, 48-86. [PubMed]

29. Lencer, W.I.; Tsai, B. The intracellular voyage of cholera toxin: Going retro. Trends Biochem. Sci. 2003, 28, 639-945. [CrossRef] [PubMed]

30. Saslowsky, D.E.; Lencer, W.I. Conversion of apical plasma membrane sphingomyelin to ceramide attenuates the intoxication of host cells by cholera toxin. Cell. Microbiol. 2008, 10, 67-80. [CrossRef] [PubMed]

31. Wolf, A.A.; Fujinaga, Y.; Lencer, W.I. Uncoupling of the cholera toxin-G(M1) ganglioside receptor complex from endocytosis, retrograde Golgi trafficking, and downstream signal transduction by depletion of membrane cholesterol. J. Biol. Chem. 2002, 277, 16249-16256. [CrossRef] [PubMed] 
32. Massol, R.H.; Larsen, J.E.; Fujinaga, Y.; Lencer, W.I.; Kirchhausen, T. Cholera toxin toxicity does not require functional Arf6- and dynamin-dependent endocytic pathways. Mol. Biol. Cell 2004, 15, 3631-3641. [CrossRef] [PubMed]

33. Chinnapen, D.J.; Hsieh, W.T.; te Welscher, Y.M.; Saslowsky, D.E.; Kaoutzani, L.; Brandsma, E.; D’Auria, L.; Park, H.; Wagner, J.S.; Drake, K.R.; et al. Lipid sorting by ceramide structure from plasma membrane to ER for the cholera toxin receptor ganglioside GM1. Dev. Cell 2012, 23, 573-586. [CrossRef] [PubMed]

34. de Gassart, A.; Géminard, C.; Février, B.; Raposo, G.; Vidal, M. Lipid raft-associated protein sorting in exosomes. Blood 2003, 102, 4336. [CrossRef] [PubMed]

35. Calzolari, A.; Raggi, C.; Deaglio, S.; Sposi, N.M.; Stafsnes, M.; Fecchi, K.; Parolini, I.; Malavasi, F.; Peschle, C.; Sargiacomo, M.; et al. TfR2 localizes in lipid raft domains and is released in exosomes to activate signal transduction along the MAPK pathway. J. Cell Sci. 2006, 119 Pt 21, 4486-4498. [CrossRef] [PubMed]

36. Parolini, I.; Federici, C.; Raggi, C.; Lugini, L.; Palleschi, S.; De Milito, A.; Coscia, C.; Iessi, E.; Logozzi, M.; Molinari, A.; et al. Microenvironmental $\mathrm{pH}$ is a key factor for exosome traffic in tumor cells. J. Biol. Chem. 2009, 284, 34211-34222. [CrossRef] [PubMed]

37. Kowal, J.; Arras, G.; Colombo, M.; Jouve, M.; Morath, J.P.; Primdal-Bengtson, B.; Dingli, F.; Loew, D.; Tkach, M.; Théry, C. Proteomic comparison defines novel markers to characterize heterogeneous populations of extracellular vesicle subtypes. Proc. Natl. Acad. Sci. USA 2016, 113, E968-E977. [CrossRef] [PubMed]

38. Almagro-Moreno, S.; Pruss, K.; Taylor, R.K. Intestinal Colonization Dynamics of Vibrio cholerae. PLoS Pathog. 2015, 11, e1004787. [CrossRef] [PubMed]

39. Tomasi, M.; Battistini, A.; Araco, A.; Roda, L.G.; D'Agnolo, G. The Role of the Reactive Disulfide Bond in the Interaction of Cholera-Toxin Functional Regions. Eur. J. Biochem. 1979, 93, 621-627. [CrossRef] [PubMed]

40. Thery, C.; Amigorena, S.; Raposo, G.; Clayton, A. Isolation and characterization of exosomes from cell culture supernatants and biological fluids. In Current Protocols in Cell Biology/Editorial Board; John Wiley \& Sons, Inc.: Hoboken, NJ, USA, 2006; pp. 3.22.1-3.22.29.

41. Kormelink, T.G.; Arkesteijn, G.J.; Nauwelaers, F.A.; van den Engh, G.; Nolte-'t Hoen, E.N.; Wauben, M.H. Prerequisites for the analysis and sorting of extracellular vesicle subpopulations by high-resolution flow cytometry. Cytom. Part A J. Int. Soc. Anal. Cytol. 2015, 89, 135-147. [CrossRef] [PubMed]

(C) 2018 by the authors. Licensee MDPI, Basel, Switzerland. This article is an open access article distributed under the terms and conditions of the Creative Commons Attribution (CC BY) license (http:/ / creativecommons.org/licenses/by/4.0/). 